\title{
Seismic Vulnerability of Building Construction Site
}

\author{
Ahmed Zahaf ${ }^{1}$ and Mahmoud Bensaibi ${ }^{2}$ \\ 1. Department of Civil Engineering, University of Blida, Blida 09000, Algeria \\ 2. Department of Material and Structures, Hight National School of Public Works, Kouba 16000, Algeria
}

\begin{abstract}
Building construction site plays an important role in the economic aspect of a region. So any disruption due to hazard event like earthquake can cause several direct and indirect damages. Direct damages can lead to the loss of equipments and qualified persons. Indirect damages can lead to inflation and loss of purchasing power. To deal with that situation, parameters that govern the vulnerability of building construction site have been identified. Using a MCDM (multiple criteria decision making) method, the priority order of these parameters has been set. Then a PVI (partial vulnerability index) and a GVI (global vulnerability index) are proposed. These indexes allow the classification of building construction sites according to their intrinsic vulnerability and seismic vulnerability respectively that is through the use of a given classification. Several Algerian building construction sites belonging to different seismic zones were considered in order to show the applicability of the method.
\end{abstract}

Key words: Seismic vulnerability, construction site, risk management, analytical hierarchy process, vulnerability index.

\section{Introduction}

One of the definition of vulnerability is the capacity of a system, a subsystem or system components to respond to a hazard or its impacts [1-3]. System vulnerability can be described as a regard to its exposure to a hazard, its capacity to resist hazard impacts, and its possibility to recover from the hazard [4]. It is necessary to identify a hazard event in order to give sense to the vulnerability. Vulnerability can be internally created and modified by organizational, social and economic factors, parameters which are not usually connected to hazard events in time and space. This means that vulnerability is not only dependent on the hazard event [5].

Even though certain factors can make damage on a system, making it vulnerable to hazard attack, these can not be dissociated from the system [2]. This is particularly true in the case of an earthquake event, affecting an industrial site (factory) where human and financial factors can not be dissociated [6-11]. The

Corresponding author: Mahmoud Bensaibi, professor, research fields: seismic vulnerability of existing structures, seismic vulnerability of lifelines, seismic scenarios, seismic risk management and torsion effect on asymmetric buildings. E-mail: bensaibim@yahoo.co.uk. purpose of vulnerability assessment is to make policies to improve adaptive capacities of a system to cope with hazard impacts $[4,2]$ especially in the case of building construction site [12,13] subjected to seismic event.

The present study deals with seismic risk management of building construction sites and aims to improve the impact of factors having an influence on the realization process of buildings. For this purpose, a vulnerability index was developed taking into account factors identified from past earthquakes. These factors were quantified using the techniques of the AHP (analytical hierarchy process) [14, 15]. The obtained index allows the classification of buildings construction site according to its degree of vulnerability. This classification was done according a developed scale.

\section{Project Risk Management}

The main purpose of the project risk management is to identify, evaluate and control the risks that might delay the progress of the construction process of a project and as a result affect its success. The success of a given project can be difficult to evaluate due to the fact that the project itself is structured in stages. 
Many stakeholders have different criteria to evaluate project success stages. However, the project success criteria are generally measured by time overrun, cost overrun and technical performance [16-18]. In the case of a building construction site the success of the project is measured by the achievement of the construction in time and with the initial estimated coast.

To study the seismic vulnerability of building construction site, four steps were defined.

Step 1: Identification of the parameters that play an important role in the vulnerability of building construction site;

Step 2: Quantification of these parameters using a MCDM (multiple criteria decision making) method;

Step 3: Definition of a vulnerability index;

Step 4: Elaboration of a scale leading to classify the element according its vulnerability index.

\section{Identified Parameters}

The main factors which govern the vulnerability of a building construction sites must be identified first. Seismic feedback experiences have allowed identifying parameters as follows.

\subsection{Human Component}

The human component is the personal staff present on the project site. This factor will be denoted $\mathrm{CH}$.

\subsection{Equipments}

The equipment requirement in a project implementation is based on the importance of the project. This factor will be denoted Eq.

\subsection{Supplies}

The supplies are all the goods and means needed by the project. This factor will be denoted Ap.

\subsection{Organization}

The organizations all the schedules made for the project realization. This factor will be denoted Og.

\subsection{Site}

A site is the location where the construction project will be implemented.

\section{Quantification of the Parameters}

For a given site or a given seismic zone, the above parameters should be quantified. Judgment and experience play an important role in this process. Multiple criteria decision making methods were often used for this purpose. In the present case, the AHP has been adopted [19, 20].

\subsection{AHP Principle}

The AHP is a decision-support tool developed by Saaty $[21,22]$. It aims to help the decision-maker facing a complex problem with multiple conflicting and subjective criteria (e.g., location or investment selection, projects ranking, and so forth).

The advantages of this approach is that it organizes tangible and intangible factors in a systematic way, and provides a structured yet relatively simple solution to the decision-making problems [21].

To perform the AHP several steps were defined [18], they are, construction of the hierarchy, setting pairs of comparison, prioritization and checking the logic consistency of the analysis [10, 21, 22]. A table was developed by Saaty (Table 1) in order to give a numerical value between two factors.

\subsection{AHP Implementation}

The hierarchy and the pair-wise comparisons being

Table 1 Gradation scale for quantitative comparison of alternatives [23].

\begin{tabular}{ll}
\hline Option & Numerical value (s) \\
\hline Equal & 1 \\
Marginally strong & 3 \\
Strong & - \\
Very strong & 7 \\
Extremely strong & 9 \\
Intermediate value to reflect fuzzy & $2,4,6,8$ \\
inputs & Reciprocals \\
Reflecting dominance of second & - \\
\hline Alternative compared with first &
\end{tabular}


performed [10, 21-23], a priority vector $E_{i}$ must be determined, this one classify the priority in an increasing or a decreasing relative order:

$$
E_{i}=\sum_{j=1}^{n} W_{i j} / n
$$

with:

$$
W_{i j}=a_{i j} / \sum_{i=1}^{n} a_{i j}
$$

where, $n$ is the matrix size and $W_{i j}$ are the elements matrix, the $a_{i j}$ are determined based on the seismic feedback experience using the relative scale measurement shown in Table 1.

Hierarchical synthesis is now used to weight the eigenvectors by the weights of the criteria and the sum is taken over all weighted eigenvector entries corresponding to those in the next lower level of the hierarchy.

Having made all the pair-wise comparisons, the consistency is determined by using the eigenvalue, $\lambda_{\max }$, to calculate the consistency index, $C I$ as follows:

$$
C I=\left(\lambda_{\max }-n\right) /(n-1)
$$

Judgment consistency can be checked by taking the $C R$ (consistency ratio) of $C I$ with the appropriate value in Table 2. The $C R$ is acceptable, if its value does not exceed 0.10 . If the value is greater, the judgment matrix is inconsistent.

\section{Vulnerability Index Method}

Within this work, two vulnerability indexes were defined. The first one was called " $P V I$ (partial vulnerability index)" and the second one was called "GVI (global vulnerability index)".

The $P V I$ was defined as the sum of the vulnerability of each parameter that has an influence on the activity of the building construction site.

The GVI takes into account the seismic zone where the project is implemented.

So with:

$E_{i}$ : priority order of the parameter calculated by the AHP;

$P$ : potential risk related to the site or to the seismic zone; $p_{i}$ : parameter value;

$n_{i}$ : referential parameter value.

The vulnerability of a parameter can be expressed by:

$$
V_{i}=E_{i}^{*} p_{i} / n_{i}
$$

The $P V I$ of a building construction site is then:

$$
P V I=\Sigma V_{i}
$$

The partial vulnerability index above does not take into account the seismic zone. This is done through the GVI.

It is defined as:

$$
G V I=P V I / P
$$

This one let the comparison between two building construction sites implemented in two different seismic zones.

According to the Algerian seismic code in use, five seismic zones are defined, from the less seismic zone to the most seismic one $(0,1,2 a, 2 b, 3)$. These ones let the determination of the potential risk $\mathrm{P}$.

\section{Proposed Classification}

A vulnerability classification of building construction site is proposed (Table 3):

The green interval means that the building construction site is not vulnerable to seismic action and therefore there is no risk of major disruptions. The

Table 2 Average random consistency (RI) [21, 22].

\begin{tabular}{ll}
\hline Size of matrix & Random consistency \\
\hline 1 & 0 \\
2 & 0 \\
3 & 0.58 \\
4 & 0.9 \\
5 & 1.12 \\
6 & 1.24 \\
7 & 1.32 \\
8 & 1.41 \\
9 & 1.45 \\
10 & 1.49 \\
\hline
\end{tabular}

Table 3 Classification of building construction site.

\begin{tabular}{llll}
\hline Class & Red & Orange & Green \\
\hline VI* & $0 \div 0.25$ & $0.25 \div 0.75$ & $0.75 \div 1$ \\
\hline
\end{tabular}

* Vulnerability index. 
red interval means that the building construction site is vulnerable to seismic action and therefore it might suffer from very important disturbances. The orange interval is an intermediate situation.

The PVI is used as a value of the VI in order to classify building constructions sites located in the same seismic zone. In this case, the seismic hazard is not taken into account.

In order to deal with the seismic aspect, the GVI is then used.

To calculate the GVI, the potential risk $\mathrm{P}$, must be determined. This one is deduced from the acceleration coefficient taken from the Algerian seismic code (RPA99) [24] (Table 4).

In the RPA99, the use group is a classification of structures according to their importance. So four groups are distinguished [24]:

- Group 1A: for strategic structures and buildings of very high importance;

- Group 1B: for important structures and buildings higher than $48 \mathrm{~m}$. Water towers are included in this group;

- Group 2: for useful structures and buildings lower than $48 \mathrm{~m}$;

- Group 3: for structures of low importance and temporary buildings.

Based on the previous table, the values of $\mathrm{P}$ are

Table 4 Acceleration coefficient according the seismic zone [24].

\begin{tabular}{lllll}
\hline \multirow{2}{*}{ Use group } & \multicolumn{4}{c}{ Seismic zone } \\
\cline { 2 - 5 } & 1 & $2 \mathrm{a}$ & $2 \mathrm{~b}$ & 3 \\
\hline 1A & 0.15 & 0.25 & 0.30 & 0.40 \\
$1 \mathrm{~B}$ & 0.12 & 0.20 & 0.25 & 0.30 \\
2 & 0.10 & 0.15 & 0.20 & 0.25 \\
3 & 0.07 & 0.10 & 0.14 & 0.18 \\
\hline
\end{tabular}

Table 5 P values.

\begin{tabular}{llllll}
\hline \multirow{2}{*}{ Use group } & \multicolumn{5}{c}{ Seismic zone } \\
\cline { 2 - 6 } & 0 & 1 & $2 \mathrm{a}$ & $2 \mathrm{~b}$ & 3 \\
\hline $1 \mathrm{~A}$ & 1 & 1.15 & 1.25 & 1.30 & 1.40 \\
$1 \mathrm{~B}$ & 1 & 1.12 & 1.20 & 1.25 & 1.30 \\
2 & 1 & 1.10 & 1.15 & 1.20 & 1.25 \\
3 & 1 & 1.07 & 1.10 & 1.14 & 1.18 \\
\hline
\end{tabular}

Table 6 Project' characteristics.

\begin{tabular}{llll}
\hline Project No. & Description & Location & Use group \\
\hline 1 & $\begin{array}{l}1,100 \text { building units } \\
\text { Secondary school with } \\
2,000 \text { training capacity }\end{array}$ & Blida & 2 \\
& $\begin{array}{l}\text { Sixteen levels tower } \\
\text { with a basement } \\
\text { including three levels }\end{array}$ & Blida & 1B \\
3 & $\begin{array}{l}\text { Office building with six } \\
\text { floors }\end{array}$ & Tissemssilt & 2 \\
4 & $\begin{array}{l}\text { Secondary school with } \\
1,200 \text { training capacity }\end{array}$ & Tissemssilt & 1B \\
5 & $\begin{array}{l}\text { Water tower with 300 } \\
\mathrm{m}^{3} \text { capacity }\end{array}$ & Tissemssilt & 1B \\
\hline
\end{tabular}

taken according to Table 5. In the case of Zone 0 , the GVI and the PVI are the same, this is correct because there is no seismic risk in this area, so only intrinsic characteristics of the building construction site play a role in its vulnerability.

\section{Applications}

The proposed method has been applied on several projects in Algeria. Three of the projects are located in the district of Blida, an area with a high potential of seismicity, Zone 3 according to the Algerian Seismic Code [24], and the three others located in the district of Tissemssilt, with lower seismic potential classified, Zone 2a according to the Algerian Seismic Code [24]. The characteristics of each project are given in Table 6 .

The parameter value $\left(p_{i}\right)$ is a score out of ten obtained by the building company for each considered parameter, taking into account the means at its disposal to carry out the project (this is a result of the tender process).

\subsection{Project 1}

The estimated cost of this project (Fig. 1) is around 30 million US\$ and the completion period is 48 months. Detailed calculations are given in Appendix 1.

7.1.1 Priority Factors and Consistency Index

Using the AHP the comparison pairs is established and $E_{i}$ (Table 7) is derived according to Eq. (2):

According to Eq. (3), $C I=0.0163$ and $R I=0.9$, so $C R=0.018$. This value is less than $10 \%$, so the 
judgment matrix is consistent.

\subsubsection{Parameters Evaluation}

After an in situ evaluation, the parameters value was derived for the different factors and the results are given in Table 8.

\subsubsection{Vulnerability Assessment}

The $P V I$ is computed and the results are given in Table 9.

$$
G V I=P V I / P=0.7542 / 1.25=0.6
$$

The PVI shows a value which is located between the two classes, the green and the orange. This shows that the risk of disturbance is not very high. However, in case of a seismic event it must be deal with it carefully since the GVI belongs to the orange range.

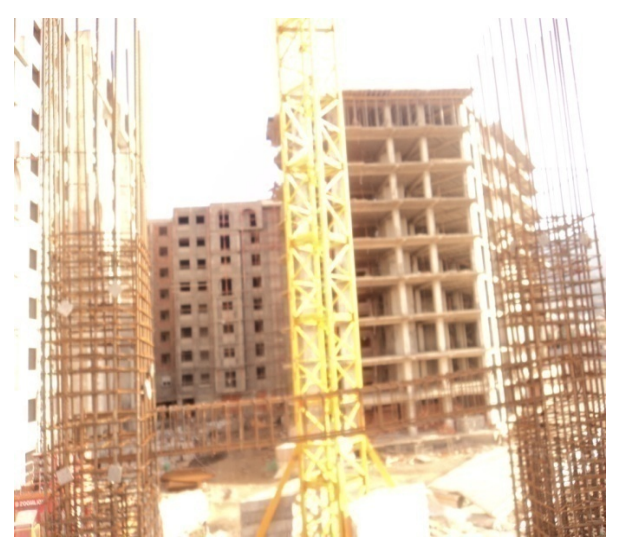

Fig. 1 Project 1 in progress.

Table 7 Project 1 decision matrix.

\begin{tabular}{llllll}
\hline & $\mathrm{CH}$ & $\mathrm{Eq}$ & $\mathrm{Ap}$ & $\mathrm{Og}$ & $E_{i}$ \\
\hline $\mathrm{CH}$ & 1 & 5 & 3 & 4 & 0.543 \\
$\mathrm{Eq}$ & $1 / 5$ & 1 & $1 / 3$ & $1 / 2$ & 0.085 \\
$\mathrm{Ap}$ & $1 / 3$ & 3 & 1 & 2 & 0.233 \\
$\mathrm{Og}$ & $1 / 4$ & 2 & $1 / 2$ & 1 & 0.14 \\
\hline
\end{tabular}

Table 8 Parameters value of the first case study.

\begin{tabular}{lllll}
\hline & $\begin{array}{l}\text { Human component Equipment } \\
\mathrm{CH} / 10\end{array}$ & $\begin{array}{l}\text { Supply } \\
\mathrm{Eq} / 10\end{array}$ & $\begin{array}{l}\text { Organization } \\
\mathrm{Ap} / 10\end{array}$ & $\mathrm{Og} / 10$ \\
\hline$p_{i}$ & 8 & 8 & 6 & 8 \\
\hline
\end{tabular}

Table 9 Vulnerability of the first case study.

\begin{tabular}{lllll}
\hline Factors & $E_{i}$ & $p_{i}$ & $n_{i}$ & $V_{i}$ \\
\hline $\mathrm{CH}$ & 0.543 & 8 & 10 & 0.4344 \\
$\mathrm{Eq}$ & 0.085 & 8 & 10 & 0.068 \\
$\mathrm{Ap}$ & 0.233 & 6 & 10 & 0.1398 \\
$\mathrm{Og}$ & 0.14 & 8 & 10 & 0.112 \\
\hline$P V I$ & & & & 0.7542 \\
\hline
\end{tabular}

\subsection{Project 2}

The estimated cost of this project (Fig. 2) is around 4 million US\$ and the completion period is 26 months.

7.2.1 Priority Factors and Consistency Index

Using the AHP the comparison pairs is established and $E_{i}$ (Table 10) is derived according to Eq. (2):

According to Eq. (3), $C R=0.03278$. This value is less than $10 \%$, so the judgment matrix is consistent.

\subsubsection{Parameters Evaluation}

After an in situ evaluation, the parameters value was derived for the different factors and the results are given in Table 11.

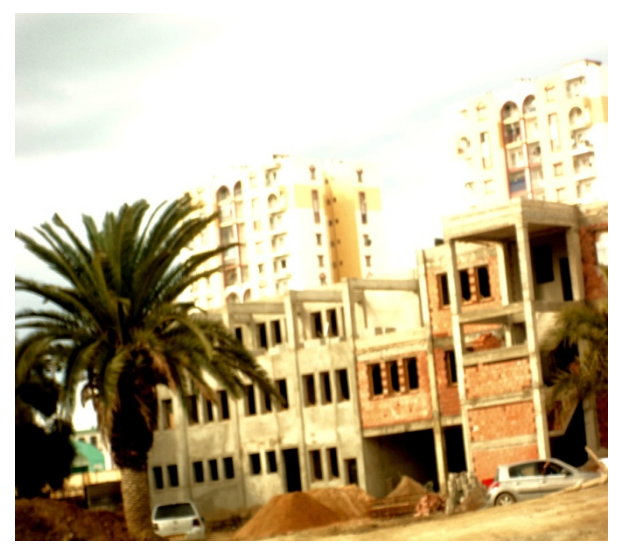

Fig. 2 The secondary school in progress.

Table 10 Project 2 decision matrix.

\begin{tabular}{llllll}
\hline & $\mathrm{CH}$ & $\mathrm{Eq}$ & $\mathrm{Ap}$ & $\mathrm{Og}$ & $E_{i}$ \\
\hline $\mathrm{CH}$ & 1 & 4 & 3 & 3 & 0.501 \\
$\mathrm{Eq}$ & $1 / 4$ & 1 & $1 / 3$ & $1 / 2$ & 0.094 \\
$\mathrm{Ap}$ & $1 / 3$ & 3 & 1 & 2 & 0.247 \\
$\mathrm{Og}$ & $1 / 3$ & 2 & $1 / 2$ & 1 & 0.158 \\
\hline
\end{tabular}

Table 11 Parameters value of the second case study.

\begin{tabular}{llll}
\hline & Human component \\
$\mathrm{CH} / 10$ & Equipment & Supply & Organization \\
$\mathrm{Eq} / 10$ & $\mathrm{Ap} / 10$ & $\mathrm{Og} / 10$ \\
\hline$p_{i} 8$ & 7 & 6 & 8 \\
\hline
\end{tabular}

Table 12 Vulnerability of the second case study.

\begin{tabular}{lllll}
\hline Factors & $E_{i}$ & $p_{i}$ & $n_{i}$ & $V_{i}$ \\
\hline $\mathrm{CH}$ & 0.502 & 8 & 10 & 0.4016 \\
$\mathrm{Eq}$ & 0.094 & 7 & 10 & 0.0658 \\
$\mathrm{Ap}$ & 0.247 & 6 & 10 & 0.1482 \\
$\mathrm{Og}$ & 0.158 & 8 & 10 & 0.1264 \\
\hline$P V I$ & & & & 0.742 \\
\hline
\end{tabular}




\subsubsection{Vulnerability Assessment}

The $P V I$ is computed and the results are given in Table 12. $G V I=P V I / P=0.742 / 1.30$ and $G V I=0.57$.

This project has a medium vulnerability since its $P V I$ and GVI belong to the orange range. The main parameters increasing its vulnerability are human component and supplies. So these two parameters should be taken into account in order to decrease the vulnerability of the project.

\subsection{Project 3}

The estimated cost of this project (Fig. 3) is around 5 million US\$ and the completion times are 48 months.

7.3.1 Priority Factors and Consistency Index

Using the AHP, the comparison pairs is established and $E_{i}$ (Table 13) is derived according to Eq. (2):

According to Eq. (3), $C R=0.03287$. This value is less than $10 \%$ so the judgment matrix is consistent.

\subsubsection{Parameters Evaluation}

After an in situ evaluation, the parameters value was derived for the different factors and the results are given in Table 14.

\subsubsection{Vulnerability Assessment}

The partial vulnerability index is computed and the results are given in Table 15. GVI $=P V I / 1.30, G V I=$ 0.59 .

Since the PVI belongs to the green range, the project has a small vulnerability. But in case of a seismic event, it must be deal with it carefully since the $G V I$ belongs to the orange range.

\subsection{Project 4}

The estimated cost of this project (Fig. 4) is around 15 million US\$ and the completion times are 48 months.

\subsubsection{Priority Factors and Consistency Index}

Using the AHP, the comparison pairs is established and $E_{i}$ (Table 16) is derived according to Eq. (2):

According to Eq. (3), $C R=0.068$. This value is less than $10 \%$ so the judgment matrix is consistent.

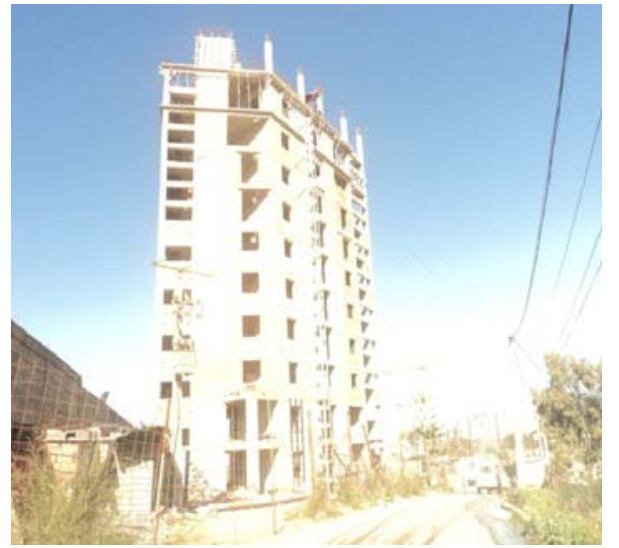

Fig. 3 Tower in progress.

Table 13 Project 3 decision matrix.

\begin{tabular}{llllll}
\hline & $\mathrm{CH}$ & $\mathrm{Eq}$ & $\mathrm{Ap}$ & $\mathrm{Og}$ & $E_{i}$ \\
\hline $\mathrm{CH}$ & 1 & 4 & 3 & 4 & 0.525 \\
$\mathrm{Eq}$ & $1 / 4$ & 1 & $1 / 3$ & $1 / 2$ & 0.093 \\
$\mathrm{Ap}$ & $1 / 3$ & 3 & 1 & 2 & 0.239 \\
$\mathrm{Og}$ & $1 / 4$ & 2 & $1 / 2$ & 1 & 0.143 \\
\hline
\end{tabular}

Table 14 Parameters value of the third case study.

\begin{tabular}{lllll}
\hline $\begin{array}{l}\text { Human } \\
\text { component } \\
\text { CH/10 }\end{array}$ & $\begin{array}{l}\text { Equipment } \\
\text { Eq/10 }\end{array}$ & $\begin{array}{l}\text { Supply } \\
\text { Ap/10 }\end{array}$ & $\begin{array}{l}\text { Organization } \\
\text { Og/10 }\end{array}$ \\
\hline$p_{i}$ & 9 & 8 & 6 & 6 \\
\hline
\end{tabular}

Table 15 Vulnerability of the third case study.

\begin{tabular}{lllll}
\hline Factors & $E_{i}$ & $p_{i}$ & $n_{i}$ & $V_{i}$ \\
\hline CH & 0.502 & 9 & 10 & 0.4518 \\
Eq & 0.094 & 8 & 10 & 0.0752 \\
Ap & 0.247 & 6 & 10 & 0.1482 \\
Og & 0.158 & 6 & 10 & 0.0948 \\
\hline$P V I$ & & & & 0.77 \\
\hline
\end{tabular}

\subsubsection{Parameters Evaluation}

After an in situ evaluation, the parameters value was derived for the different factors and the results are given in Table 17.

\subsubsection{Vulnerability Assessment}

The partial vulnerability index is computed and the results are given in Table 18. GVI $=P V I / P=0.77 / 1.15$, so $G V I=0.67$.

Since the PVI belongs to the green range, the project has a small vulnerability. But this vulnerability increase in the case of seismic event. This is highlighted by the $G V I$ which belongs to the orange range. 


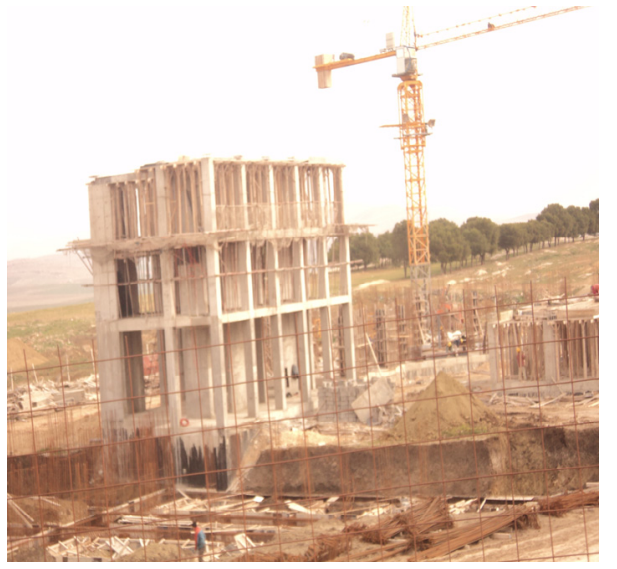

Fig. 4 Office building in progress.

Table 16 Project 4 decision matrix.

\begin{tabular}{llllll}
\hline & $\mathrm{CH}$ & $\mathrm{Eq}$ & $\mathrm{Ap}$ & $\mathrm{Og}$ & $E_{i}$ \\
\hline $\mathrm{CH}$ & 1 & 3 & 4 & 5 & 0.520 \\
$\mathrm{Eq}$ & $1 / 3$ & 1 & 3 & 4 & 0.268 \\
$\mathrm{Ap}$ & $1 / 4$ & $1 / 3$ & 1 & 3 & 0.141 \\
$\mathrm{Og}$ & $1 / 5$ & $1 / 4$ & $1 / 3$ & 1 & 0.071 \\
\hline
\end{tabular}

Table 17 Parameters value of the forth case study.

\begin{tabular}{lllll}
\hline & Human component & \multicolumn{2}{l}{ Equipment Supply } & Organization \\
& $\mathrm{CH} / 10$ & $\mathrm{Eq} / 10$ & $\mathrm{Ap} / 10$ & $\mathrm{Og} / 10$ \\
\hline$p_{i}$ & 8 & 8 & 7 & 6 \\
\hline
\end{tabular}

Table 18 Vulnerability of the forth case study.

\begin{tabular}{lllll}
\hline Factors & $E_{i}$ & $p_{i}$ & $n_{i}$ & $V_{i}$ \\
\hline $\mathrm{CH}$ & 0.520 & 8 & 10 & 0.416 \\
$\mathrm{Eq}$ & 0.268 & 8 & 10 & 0.2144 \\
$\mathrm{Ap}$ & 0.141 & 7 & 10 & 0.0987 \\
$\mathrm{Og}$ & 0.071 & 6 & 10 & 0.0426 \\
\hline$P V I$ & & & & 0.7717 \\
\hline
\end{tabular}

\subsection{Project 5}

The estimated cost of this project (Fig. 5) is around 6 million US\$ and the completion times are 48 months.

7.5.1 Priority Factors and Consistency Index

Using the AHP the comparison pairs is established and $E_{i}$ (Table 19) is derived according to Eq. (2).

According to Eq. (3), $\mathrm{CR}=0.063$. This value is less than $10 \%$, so the judgment matrix is consistent.

\subsubsection{Parameters Evaluation}

After an in situ evaluation, the parameters value was derived for the different factors and the results are given in Table 20.

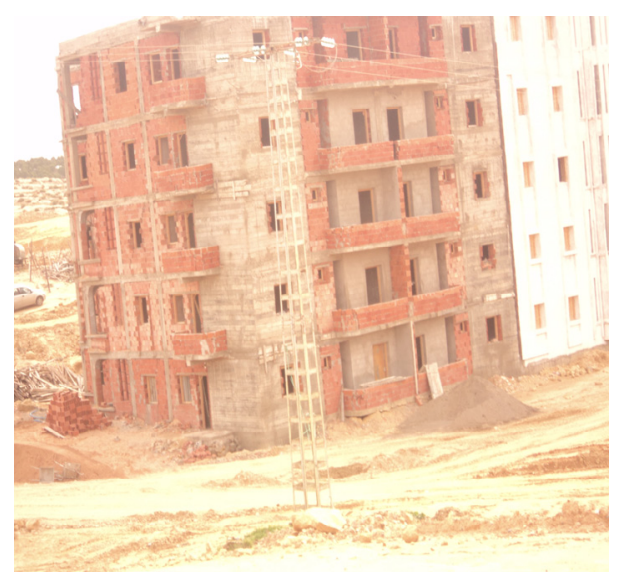

Fig. 5 Project 5 in progress.

Table 19 Project 5 decision matrix.

\begin{tabular}{llllll}
\hline & $\mathrm{CH}$ & $\mathrm{Eq}$ & $\mathrm{Ap}$ & $\mathrm{Og}$ & $E_{i}$ \\
\hline $\mathrm{CH}$ & 1 & 5 & 4 & 3 & 0.543 \\
$\mathrm{Eq}$ & $1 / 5$ & 1 & $1 / 2$ & $1 / 3$ & 0.086 \\
$\mathrm{Ap}$ & $1 / 4$ & 2 & 1 & 2 & 0.189 \\
$\mathrm{Og}$ & $1 / 3$ & 2 & $1 / 2$ & 1 & 0.182 \\
\hline
\end{tabular}

Table 20 Parameters value of the fifth case study.

\begin{tabular}{lllll}
\hline & $\begin{array}{l}\text { Human component Equipment } \\
\mathrm{CH} / 10\end{array}$ & $\begin{array}{l}\text { Supply } \\
\mathrm{Eq} / 10\end{array}$ & $\begin{array}{l}\text { Organization } \\
\mathrm{Ap} / 10\end{array}$ \\
\hline$p_{i}$ & 7 & 8 & 8 & 7 \\
\hline
\end{tabular}

Table 21 Vulnerability of the fifth case study.

\begin{tabular}{lllll}
\hline Factors & $E_{i}$ & $p_{i}$ & $n_{i}$ & $V_{i}$ \\
\hline CH & 0.543 & 7 & 10 & 0.3801 \\
Eq & 0.086 & 8 & 10 & 0.0688 \\
Ap & 0.189 & 8 & 10 & 0.1512 \\
Og & 0.182 & 7 & 10 & 0.1274 \\
\hline$P V I$ & & & & 0.7275 \\
\hline
\end{tabular}

\subsubsection{Vulnerability Assessment}

The partial vulnerability index is computed and the results are given in Table 21. GVI $=P V I / P=$ $0.7275 / 1.20$, so $G V I=0.61$.

The PVI and the GVI belongs to the orange range, indicating that the project has a medium vulnerability.

\subsection{Project 6}

The estimated cost of this project (Fig. 6) is around 8 million US\$ and the completion times are 48 months.

7.6.1 Priority Factors and Consistency Index

Using the AHP, the comparison pairs is established and $E_{i}$ (Table 22) is derived according to Eq. (2). 
According to Eq. (3), $C R=0.060$. This value is less than $10 \%$ so the judgment matrix is consistent.

\subsubsection{Parameters Evaluation}

After an in situ evaluation, the parameters value was derived for the different factors and the results are given in Table 23.

\subsubsection{Vulnerability Assessment}

The partial vulnerability index is computed and the results are given in Table 24. GVI $=P V I / P=$ $0.8119 / 1.20$, so $G V I=0.68$.

The $P V I$ belongs to the green range, the project has a small intrinsic vulnerability, but seismic risk increase it vulnerability, so according to the GVI, this building construction site is classify orange.

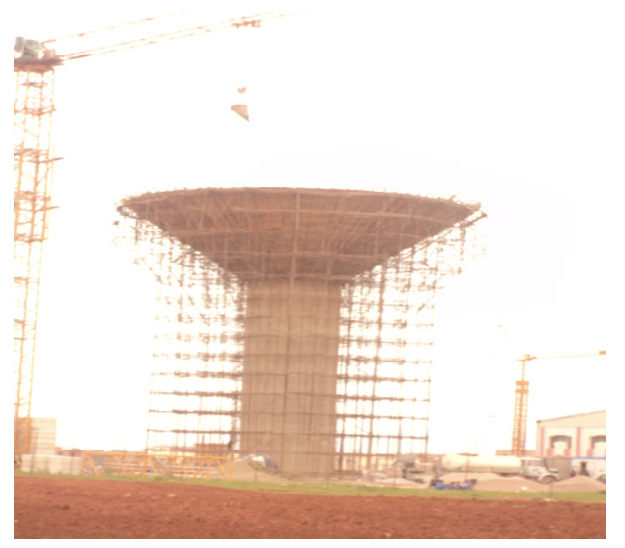

Fig. 6 Water tower in progress.

Table 22 Project 6 decision matrix.

\begin{tabular}{llllll}
\hline & $\mathrm{CH}$ & $\mathrm{Eq}$ & $\mathrm{Ap}$ & $\mathrm{Og}$ & $E_{i}$ \\
\hline $\mathrm{CH}$ & 1 & 6 & 4 & 3 & 0.556 \\
$\mathrm{Eq}$ & $1 / 6$ & 1 & $1 / 2$ & $1 / 3$ & 0.079 \\
$\mathrm{Ap}$ & $1 / 3$ & 3 & 1 & 2 & 0.189 \\
$\mathrm{Og}$ & $1 / 3$ & 2 & $1 / 2$ & 1 & 0.175 \\
\hline
\end{tabular}

Table 23 Parameters value of the sixth case study.

\begin{tabular}{lllll}
\hline & Human component & Equipment \\
& $\mathrm{CH} / 10$ & Eq/10 & Supply & Organization \\
$\mathrm{Ap} / 10$ & $\mathrm{Og} / 10$ \\
\hline$p_{i}$ & 9 & 7 & 8 & 6 \\
\hline
\end{tabular}

Table 24 Vulnerability of the sixth case study.

\begin{tabular}{lllll}
\hline Factors & $E_{i}$ & $p_{i}$ & $n_{i}$ & $V_{i}$ \\
\hline $\mathrm{CH}$ & 0.556 & 9 & 10 & 0.5004 \\
$\mathrm{Eq}$ & 0.079 & 7 & 10 & 0.0553 \\
$\mathrm{Ap}$ & 0.189 & 8 & 10 & 0.1512 \\
$\mathrm{Og}$ & 0.175 & 6 & 10 & 0.105 \\
\hline$P V I$ & & & & 0.8119 \\
\hline
\end{tabular}

As can be seen from the results, the building construction sites of Zone $2 \mathrm{a}$ are less vulnerable than those of Zone 3. The most vulnerable project is the project 2, the least one is Project 6 .

\section{Conclusions}

What can be drawn from this study is that seismic vulnerability studies carried on buildings construction sites can highlight weak points and help project managers to reduce/or protect the site from any seismic resulting hazard. Parameters such as human component, organization, supplies, equipment are main components defining the seismic vulnerability of a given construction site. Indeed, defining the priority order of such component is of great importance to approach its vulnerability. In this study, this order has been obtained using the AHP method. More ever, vulnerability classification was made on the base of the developed parameters $P V I$ and $G V I$.

\section{References}

[1] R. Chambers, Vulnerability, coping and policy (editorial introduction), IDS Bulletin 37 (4) (2006) 33-40.

[2] P.M. Kelly, W.N. Adger, Theory and practice in assessing vulnerability to climate change and facilitating adaptation, Climatic Change 47 (4) (2000) 325-352.

[3] B.L. Turner, R.E. Kasperson, P.A. Matson, J.J. MacCarthy, R.W. Corell, L. Christensen, et al., A framework for vulnerability analysis in sustainability science, Proceeding of the National Academy of Sciences of USA 100 (14) (2003) 8074-8079.

[4] M.J. Watts, H.G. Bohle, The space of vulnerability: The causal structure of hunger and famine, Progress in Human Geography 17 (1) (1993) 43-67.

[5] N. Brooks, Vulnerability, risk and adaptation: A conceptual framework, Working Paper 38, Tyndall Centre for Climate Change Research, Nov. 2003.

[6] K.A. Korkmaz, A. Sari, A. Suman, I. Carhoglu, Seismic risk assessment of storage tanks in Turkish industrial Industries, Journal of Loss Prevention in the Process Industries 24 (4) (2011) 314-320.

[7] E. Salzano, A.G. Agreda, A. di Carluccio, G. Fabbrocino, Risk assessment and early warning system for industrial facilities in seismic zones, Reliability Engineering and System Safety 94 (10) (2009) 1577-1584.

[8] I. Dikmen, M.T. Birgonul, C. Anac, J.H.M. Tah, G. Aouad, Learning from risks: A tool for post-project risk 
assessment, Automation in Construction 18 (2008) 42-50.

[9] E. Lee, Y. Park, J.G. Shin, Large engineering project risk management using a Bayesian belief network, Expert Systems with Applications 36 (2009) 5880-5887.

[10] A.S. Akintoye, M.J. MacLeod, Risk analysis and management in construction, International Journal of Project Management 15 (1) (1997) 31-38.

[11] C.H. Tsai, C.W. Chen, An earthquake disaster management mechanism based on risk assessment information for the tourism industry-A case study from the island of Taiwan, Tourism Management 31 (2010) 470-481.

[12] J. Zeng, M. An, N.J. Smith, Application of a fuzzy based decision making methodology to construction project risk assessment, International Journal of Project Management 25 (2007) 589-600.

[13] H. Zhang, A redefinition of the project risk process: Using vulnerability to open up the event-consequence link, International Journal of Project Management 25 (2007) 694-701.

[14] A. Zahaf, M. Bensaibi, Vulnerability assessment of a building construction site in Algeria, in: First Moroccan Spanish Colloquium on Seismic Engineering, Tangier, Morroco, Jan. 25, 2011.

[15] A. Zahaf, M. Bensaibi, Seismic risk management of building construction sites, in: 18th Congress on Risk Management and Safety Operation, Tours, France, Oct. 16-18, 2012.
[16] D. Baccarini, R. Archer, The risk ranking of projects: A methodology, International Journal of Project Management 19 (3) (2001) 139-145.

[17] T.M. Williams, Risk management infrastructure, International Journal of Project Management 11 (1) (1993) 5-10.

[18] T. Williams, A classified bibliography of recent research relating to project risk management, European Journal of Operational Research 85 (1) (1995) 18-38.

[19] E. Triantaphyllou, S.H. Mann, Using the analytic hierarchy process for decision making in engineering applications: Some challenges, International Journal of Industrial Engineering: Applications and Practice 2 (1) (1995) 35-44.

[20] K.M.A. Al-Harbi, Application of the AHP in project management, International Journal of Project Management 19 (2001) 19-27.

[21] T.L. Saaty, Multicriteria Decision Making: The Analytic Hierarchy Process, RWS Publications, Pittsburgh, 1996.

[22] T.L. Saaty, Group decision making and the AHP, in: B.L. Golden, E.A. Wasil, P.T. Harker (Eds.), The Analytic Hierarchy Process: Application and Studies, Springer, New York, 1989.

[23] B. Navneet, R. Kanwal, Strategic Decision Making Applying the Analytic Hierarchy Process, Springer-Verlag, London, 2004.

[24] Ministry of Housing, Algerian Seismic Code RPA99 Version 2003, Algeria, 2003.

\section{Appendix A: Project 1 Detailed Calculation.}

Let put: $C_{i j}=\sum_{i=1}^{n} a_{i j}$; here $n=4$, so:

$$
\begin{aligned}
& C_{11}=1+1 / 5+1 / 3+1 / 4=107 / 60 \\
& C_{21}=5+1+3+2=11 \\
& C_{31}=3+1 / 3+1+1 / 2=29 / 6 \\
& C_{41}=4+1 / 2+2+1=15 / 2
\end{aligned}
$$

According Eq. (2):

$$
W_{i j}=\left[\begin{array}{ccccc}
\frac{1}{107 / 60} & \frac{5}{11} & \frac{3}{29 / 6} & \frac{4}{15 / 2} \\
\frac{1 / 5}{107 / 60} & \frac{1}{11} & \frac{1 / 3}{29 / 6} & \frac{1 / 2}{15 / 2} \\
\frac{1 / 3}{107 / 60} & \frac{3}{11} & \frac{1}{29 / 6} & \frac{2}{15 / 2} \\
\frac{1 / 4}{107 / 60} & \frac{2}{11} & \frac{1 / 2}{29 / 6} & \frac{1}{15 / 2}
\end{array}\right]
$$

Then applying Eq. (1) leads to: 


$$
E_{i}=\frac{1}{4}\left[\begin{array}{l}
\frac{1}{107 / 60}+\frac{5}{11}+\frac{3}{29 / 6}+\frac{4}{15 / 2} \\
\frac{1 / 5}{107 / 60}+\frac{1}{11}+\frac{1 / 3}{29 / 6}+\frac{1 / 2}{15 / 2} \\
\frac{1 / 3}{107 / 60}+\frac{3}{11}+\frac{1}{29 / 6}+\frac{2}{15 / 2} \\
\frac{1 / 4}{107 / 60}+\frac{2}{11}+\frac{1 / 2}{29 / 6}+\frac{1}{15 / 2}
\end{array}\right]
$$

Then:

$$
C R=\frac{C I}{R I}
$$

$C I$ is calculated according Eq. (3) with:

$$
\lambda \underset{\max }{n}=\frac{1}{n} \sum_{i=1}^{n} \sum_{j=1}^{n} a_{i j} E_{i} / E_{i}
$$

and $R I$ is determined from Table 2 , so $R I=0.9$, then:

$$
\lambda_{\max }=\frac{1}{4}\left[\begin{array}{c}
\frac{1}{0.543}(1 \times 0.543+5 \times 0.085+3 \times 0.233+4 \times 0.14)+ \\
\frac{1}{0.085}(1 / 5 \times 0.543+1 \times 0.085+1 / 3 \times 0.233+1 / 2 \times 0.14)+ \\
\frac{1}{0.233}(1 / 3 \times 0.543+3 \times 0.085+1 \times 0.233+2 \times 0.14)+ \\
\frac{1}{0.14}(1 / 4 \times 0.543+2 \times 0.085+1 / 2 \times 0.233+1 \times 0.14)
\end{array}\right] \lambda_{\max }=4.049
$$

